\title{
Representações sociais de pobreza construídas pelos cursistas da Especialização Educação, Pobreza e Desigualdade Social realizada no Rio Grande do Norte: primeiros resultados ${ }^{*}$
}

\section{Social representations of poverty built by post-graduation students of the course about Education, Poverty and Social Inequality held in the Rio Grande do Norte state: first results}

\author{
Eliana Andrade da Silva** \\ Kilza Fernanda Moreira de Viveiros ${ }^{* *}$
}

\begin{abstract}
RESUMO
As representações sociais são uma modalidade de conhecimento produzido pelo senso comum que têm por função precípua a elaboração de comportamentos e a comunicação entre os indivíduos. Toda representação social é a leitura particular de um objeto, realizada por um sujeito (individual ou coletivo), a partir das crenças, valores e informações que compartilha na cultura na qual se situa. Apoiando-se nessa teoria, a presente pesquisa buscou identificar e conhecer a estrutura da representação social ou das representações sociais sobre o objeto simbólico "pobreza", construídas pelos cursistas da Especialização em Educação, Pobreza e Desigualdade Social
\end{abstract}

DOI: $10.1590 / 0104-4060.51389$

* Esta pesquisa foi financiada pela Secretaria de Educação Continuada, Alfabetização, Diversidade e Inclusão (Secadi), do Ministério da Educação, em parceria com a Universidade Federal do Rio Grande do Norte (UFRN).

** Universidade Federal do Rio Grande do Norte. Natal, Rio Grande do Norte, Brasil. Av. Sen. Salgado Filho - Lagoa Nova, Natal. CEP: 59064-741. E-mail: andradelili@yahoo.com.br, Kilza.fernanda@hotmail.com. 
no estado do Rio Grande do Norte. O universo da pesquisa foi composto por 301 estudantes que responderam a um questionário de livre associação de palavras, cujos dados foram analisados com o apoio do software EVOC. Com base na abordagem do núcleo central das representações sociais, de Jean-Claude Abric, foi possível identificar a estrutura dos conteúdos representacionais compartilhados pelos sujeitos investigados. Nessa estrutura, encontra-se um sistema central composto pelos elementos "desigualdade" e "exclusão" e um periférico, composto por falta, fome, miséria, necessidade. Os resultados indicam a existência de duas representações sociais: uma de caráter ideológico, que enfatiza os aspectos macroeconômicos e políticos ou o papel da educação na produção do fenômeno, e outra que considera a pobreza como parte da realidade social, portanto, sem críticas de caráter econômico ou político.

Palavras-chave: Pobreza. Representações sociais. Núcleo central.

\begin{abstract}
Social representations are a modality of knowledge produced by common sense that have as their primary function the elaboration of behaviors and communication between individuals. All social representation is the particular reading of an object, performed by a subject (individual or collective), based on the beliefs, values and information that the same shares in the culture in which they are located. Following this theory, the present research sought to identify and know the structure of social representation or social representations about "poverty" constructed by the EPSI' students in the state of Rio Grande do Norte. The research universe was composed of 301 students who answered a free word evocation questionnaire, whose data were analyzed with the support of EVOC software. Based on Jean-Claude Abric's central nucleus approach to social representations, it was possible to identify the structure of the representational contents shared by the subjects investigated. In this structure, there is a central system composed of the elements "inequality" and "exclusion" and a peripheral system composed of the elements shortage, hunger, misery, necessity. The results indicate the existence of two social representations: one of ideological character, which emphasizes the macroeconomic and political aspects or the role of education in the production of the phenomenon and another, that considers poverty as part of social reality, therefore without criticism of an economic or political nature.
\end{abstract}

Keywords: Poverty. Social representations. Central nucleus. 


\section{Introdução}

"Educação, Pobreza e Desigualdade Social” é uma iniciativa, no âmbito do Ministério da Educação, vinculada à Secretaria de Educação Continuada, Alfabetização, Diversidade e Inclusão - Secadi. Trata-se de uma ação articulada aos sistemas de ensino que implementam políticas educacionais nas áreas de Alfabetização, Diversidade e Inclusão, tendo as universidades públicas federais como instâncias executoras. O projeto inicial aspirava envolver trinta universidades, sendo quinze na primeira etapa e posteriormente nas demais. A Universidade Federal do Rio Grande do Norte - UFRN, instituição executora, foi submetida ao edital para participação na primeira etapa, por meio do Comitê de Formação Continuada - COMFOR, vinculado à Pró-Reitoria de Pós-Graduação.

Realizado todo o processo de organização gestora e de descentralização de recursos, foram constituídos a equipe pedagógica e o Grupo de Trabalho Institucional, representados pela União Nacional dos Dirigentes Municipais de Educação - UNDIME e pela Coordenação do Sistema Presença na Secretaria Estadual de Educação e Cultura do RN - SEEC, com o intuito de alcançar os sujeitos do processo de formação, constituindo uma ação voltada à formação continuada de profissionais que atuam na educação básica e/ou em políticas sociais que estabeleçam relações entre educação, pobreza e desigualdade social.

Prioritariamente, a iniciativa atende a qualificação das demandas de gestores e gestoras, professores e professoras da rede de educação básica pública, gestores do programa social Bolsa Família e profissionais do campo da assistência social. Tal processo formativo insere-se no contexto da Política Nacional de Formação dos(as) Profissionais do Magistério da Educação Básica e da Rede Nacional de Formação Continuada dos(as) Profissionais do Magistério da Educação Básica Pública e a sua organização prioriza o ensino, a pesquisa e a divulgação de conhecimentos.

De acordo com o estudo desenvolvido pela Organização das Nações Unidas, entre 2004 e 2013, os índices de pobreza no Brasil caíram de 20\% para $9 \%$ da população e de $7 \%$ para $4 \%$ no caso da pobreza extrema, no entanto, permanecem presentes no meio rural e nas regiões Norte e Nordeste. Diante dessa realidade e da constatação de sua insistência, a Iniciativa Educação, Pobreza e Desigualdade Social constata que a pobreza não deixa de existir quando crianças e jovens entram na escola; ao contrário, suas implicações manifestam-se de maneira decisiva nos espaços de educação. Foi com base nessas constatações que a Iniciativa, no âmbito do estado do Rio Grande do Norte, estabeleceu, dentre seus objetivos, promover reflexões e discussões sobre as vivências em 
circunstâncias de pobreza e extrema pobreza, bem como em relações sociais e políticas injustas. Confrontar essas vivências com as visões predominantes nas políticas educacionais, na gestão da educação e no contexto escolar da educação básica é um dos principais desafios. Por isso a Iniciativa tem por objetivo promover a práxis em torno de princípios político-ético-emancipatórios que são assentados no direito à vida, à igualdade e à diversidade.

Dentro do objetivo de contribuir para a inclusão de crianças, adolescentes e jovens em processo de escolarização, a Iniciativa tem buscado estimular, principalmente junto aos profissionais envolvidos com escolas públicas, a reflexão acerca da pobreza e da pobreza extrema vividas em nove polos de EaD da UFRN, de modo que se buscou contemplar estrategicamente todos os municípios do estado do Rio Grande do Norte envolvidos com ela, a saber: Natal, Parnamirim, Macau, Santa Cruz, Caraúbas, Currais Novos, Caicó, Martins e Grossos. A Iniciativa efetivou sua intervenção nessa realidade social, por meio da educação, ao oferecer um curso de especialização a distância para 400 educadores e ao fazer uma pesquisa científica, a qual buscou conhecer com maior profundidade determinados aspectos simbólicos que norteiam as práticas dos profissionais vinculados ao referido curso. Compreendendo a escola e sua função política e social como lócus de garantia de uma realidade mais humana, mais digna para a infância e para a adolescência, que são sujeitos históricos e de direitos, é que a UFRN, ao longo de, aproximadamente, dezoito meses (28 de agosto de 2015 a 31 de janeiro de 2017), encerrou a modalidade da especialização em Educação, Pobreza e Desigualdade Social com 358 trabalhos defendidos, entre trabalhos de conclusão de curso e artigos, com um índice de evasão menor que $8 \%$.

O presente artigo apresenta os resultados gerais da pesquisa realizada ao longo do período de duração do curso, a qual teve como objetivo principal conhecer como os cursistas constroem e compartilham suas representações sociais sobre o objeto simbólico "pobreza" e como essas "verdades" de senso comum orientam suas práticas em relação ao fenômeno da pobreza e das desigualdades sociais. Para tanto, e considerando-se os limites do espaço desta publicação, a exposição está assim estruturada: a) apresentação dos fundamentos teóricos que guiaram a escolha do objeto e orientaram as estratégias metodológicas desenvolvidas; b) apresentação dos resultados referentes à estruturação do conteúdo representacional sobre o objeto predominantemente compartilhado pelos cursistas; c) explicitação da estrutura de cada uma das duas representações sociais identificadas; d) discussão das implicações práticas desses resultados para as estratégias de enfrentamento do fenômeno da pobreza e das desigualdades sociais. 


\section{A Teoria das Representações Sociais}

A Teoria das Representações Sociais, criada por Serge Moscovici (1978), serve à pesquisa de determinado tipo de produção mental e simbólica presente no senso comum. O autor considera que toda representação social é a representação de um objeto, construída por um sujeito, num determinado contexto social. Dessa forma, toda representação social é a leitura particular de um objeto, realizada por um sujeito (individual ou coletivo), a partir das crenças, dos valores e das informações que compartilha na cultura na qual se situa. Um objeto representacional não existe em si mesmo, mas para o indivíduo ou grupo, por essa razão deve ser consistente com o sistema de avaliação utilizado por estes. Para Moscovici (1978, p. 26), as representações sociais constituem “[...] uma modalidade de conhecimento particular que tem por função a elaboração de comportamentos e de comunicação entre indivíduos". Nesse sentido, elas orientam os indivíduos na apreensão e interpretação do mundo e na organização das suas condutas e formas de comunicação.

Moscovici parte de uma abordagem diferente da relação Sujeito-Objeto, tal como desenvolvida pela Psicologia Clássica e pelo objetivismo presente na elaboração durkheimiana do conceito de representações coletivas, na qual se inspirou. Para ele, não existe corte nem separação entre o universo exterior e o universo interior do indivíduo ou grupo. O objeto representado faz parte de um contexto ativo, sendo concebido, pelo menos parcialmente, pela pessoa ou pelo grupo, enquanto prolongamento do seu comportamento. Sendo assim, o estímulo e a resposta são indissociáveis, posto que se formam ao mesmo tempo. De certa forma, a resposta já está na origem do estímulo, o que significa que este último é determinado em grande parte pela resposta. Como exemplifica Abric (1994, 2000), se um indivíduo ou grupo exprime uma opinião (ou seja, uma resposta) com relação a determinado objeto ou situação, essa opinião é, de certa forma, constitutiva do próprio objeto, pois este deve ser construído de forma a ser consistente com o sistema utilizado pelo indivíduo. Repetindo o que disse Moscovici, em sua obra clássica La psychanalyse, son image et son public (1978), um objeto não existe em si mesmo, ele existe para o indivíduo ou o grupo e em relação a eles. Daí também deriva outro "axioma" difundido por Jodelet: uma representação social é uma forma de conhecimento socialmente elaborada e compartilhada, tendo um objetivo prático "e concorrendo à construção de uma realidade comum a um conjunto social" (JODELET, 2001, p. 24).

Do ponto de vista que nos interessa aqui, é importante destacar que Moscovici considera as representações sociais enquanto sistemas de preconcepções, 
de imagens e valores, detentoras de uma significação cultural própria e sobrevivendo independentemente das experiências individuais, sendo-nos impostas sem o nosso consentimento, portanto, de forma não necessariamente consciente. Daí a importância de conhecermos como os cursistas constroem e compartilham "suas verdades" (representações sociais) sobre o objeto simbólico "pobreza" e, o mais importante do ponto de vista de uma psicossociologia voltada para a intervenção, orientam suas práticas em relação a estas. Como destaca Domingos Sobrinho (2000, p. 119), “[...] a construção das representações não se dá, por conseguinte, num vazio social. Elas são construídas por sujeitos que ocupam uma determinada posição no espaço social (...)". Não se confundem, por essa razão, com uma mera atividade cognitiva de classificação e ordenação dos objetos sociais. Assim, ao apreendermos os conteúdos representacionais partilhados pelos cursistas e conhecermos alguns dados que os situam socialmente, podemos também compreender alguns referentes culturais que os orientam na classificação e qualificação do objeto representado.

\section{A teoria complementar do Núcleo Central}

Para Abric (1994, 2000), o formulador da teoria do núcleo central, considerada uma teoria complementar à das Representações Sociais, parte da hipótese de que a organização do conteúdo de uma representação social apresenta uma característica particular, pois, não apenas os elementos que o compõem são hierarquizados, mas também organizados em torno de um núcleo constituído de um ou mais elementos que dão significado à representação. Em torno desse núcleo, situam-se os elementos periféricos explicitadores das especificidades dos indivíduos que compartilham um mesmo sentido atribuído a determinado objeto.

Apoiado nas pesquisas experimentais sobre percepção e representações sociais, Abric defendeu que a estrutura imagética ou o núcleo figurativo de uma representação é o produto das características do objeto que tenham sido selecionadas pelos indivíduos ao representá-lo. No caso desta pesquisa, por exemplo, dentre os elementos imagéticos mais compartilhados pelos cursistas a respeito do objeto "pobreza" encontram-se "fome", "miséria", "sofrimento". Esses elementos são descontextualizados, em relação, por exemplo, à multidimensionalidade da produção do fenômeno, reorganizados em uma nova estrutura de conjunto e deles retidas apenas certas qualidades icônicas, passando a gozar de uma considerável autonomia em relação ao objeto original. Por essa razão, dentre as funções exercidas pelos elementos do núcleo central, está a de 
resistir às ressignificações que eventualmente surjam a partir da incorporação de novas informações e situações vividas pelos sujeitos.

O núcleo central é fundamentalmente determinado pelo social, estando estreitamente vinculado às condições históricas, sociológicas e ideológicas de formação das representações; por isso, é "[...] a base comum propriamente social e coletiva que define a homogeneidade de um grupo, através dos comportamentos individualizados que podem parecer contraditórios" (ABRIC, 2000, p. 33, grifos do autor). É, portanto, imprescindível a estabilidade e a coerência da representação para assegurar a sua manutenção no tempo.

\section{O método de identificação dos elementos centrais de uma representação social por meio da Técnica de Associação Livre de Palavras (TALP)}

Dentre os métodos indicados por Jean-Claude Abric para a apreensão dos possíveis elementos centrais e estruturantes do conteúdo de uma representação social, utilizamos aqui o método que se apoia na Técnica de Associação Livre de Palavras ou expressões (TALP). Esta escolha se justifica principalmente pelo aspecto espontâneo e a dimensão projetiva da TALP, facilitadora, portanto, do acesso aos elementos constituintes do universo semântico da representação. Todavia, ressalte-se que, se essa técnica é eficaz para a coleta dos elementos constitutivos do conteúdo das representações, as evocações dela resultantes veiculam um significado associativo, não constituindo, por conseguinte, o todo do significado. De qualquer forma, como diz Abric (1994, p. 66), é possível obter-se um acesso mais rápido e fácil aos elementos semânticos constitutivos da representação por meio da associação livre do que por meio de entrevistas. Além do mais, a associação livre permite a "atualização de elementos implícitos ou latentes que seriam perdidos ou mascarados nas produções discursivas".

Essa técnica consiste em pedir aos sujeitos que, estimulados por um termo ou expressão indutora, geralmente o próprio rótulo verbal que designa o objeto da representação (nesta pesquisa a expressão "Pobreza é...”), enunciem as palavras que lhes vêm à mente. Comumente se pede para "dizer" as três primeiras palavras, isto no caso de se fazer a aplicação da técnica de forma oral, ou até cinco ou seis, no máximo, quando se pede as respostas por escrito. No nosso caso, optamos por cinco, deixando, portanto, cinco espaços para serem preenchidos, evitando que se ultrapassasse esse número, pois, segundo as orientações de Oliveira et al. (2005), não é aconselhável exceder esse quantitativo, já que um 
número acima deste redundaria em ineficácia da aplicação, pois o respondente tenderia a diminuir a agilidade de suas respostas e passaria a elaborar um raciocínio para as evocações seguintes, sacrificando a espontaneidade do processo. Na Figura 1, apresentamos o modelo de questionário utilizado.

\section{FIGURA 1 - QUESTIONÁRIO DA TÉCNICA DE ASSOCIAÇÃO LIVRE DE PALAVRAS (TALP)}

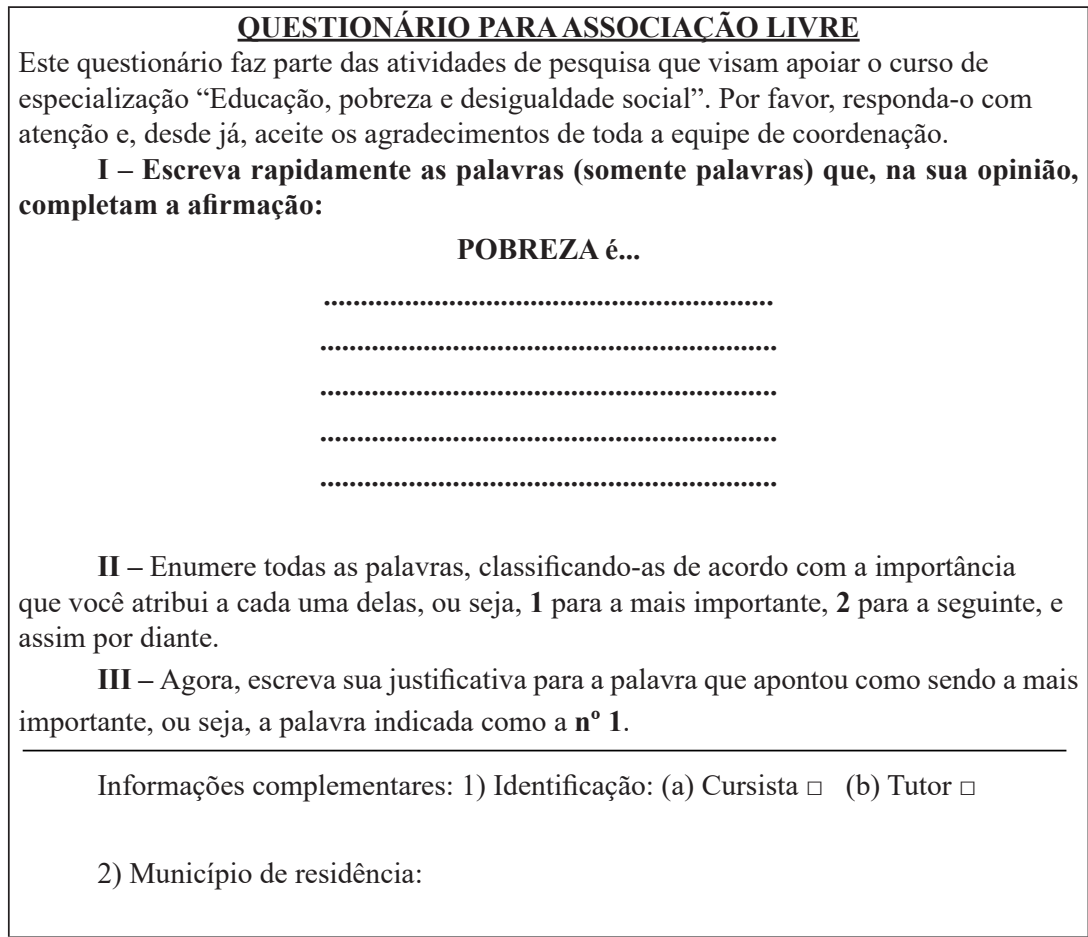

FONTE: crédito das autoras.

\section{Campo de observação e caracterização do universo da pesquisa}

De acordo com as orientações nacionais do curso de especialização, a população investigada se constituiu de cursistas vinculados a esta, residentes em vários municípios do estado. A coleta dos dados da TALP foi realizada de uma só vez durante a aula inaugural ocorrida em 28 de agosto de 2015. Foram 
entregues 377 questionários, número correspondente ao total de presentes (embora houvesse 400 matriculados), mas somente 301 preencheram o instrumento.

Os dados indicam que o grupo pesquisado é composto majoritariamente por profissionais da área de serviço social (42\%), seguido por profissionais da área de Educação (26\%). No entanto, também foram identificados profissionais com formação em Nutrição, Psicologia, licenciados em Geografia, em Letras, em Matemática, em História, em Ciências Biológicas e ainda cientistas agrários, cientistas sociais e gestores públicos, porém, em percentuais muito baixos. De modo geral, todos atuam no contexto da pobreza e da desigualdade social. Os/ as profissionais da área de Serviço Social atuam na implementação de políticas e programas de assistência social, como o Bolsa Família, e atuam igualmente em espaços ocupacionais como o Centro de Referência em Assistência Social CRAS ou o Centro de Referência Especializado em Assistência Social - CREAS, enquanto os da área de Educação atuam diretamente nas escolas públicas e se defrontam com as expressões da pobreza em seu cotidiano de trabalho, através do contato direto com os alunos que se encontram nessa condição.

O perfil do grupo indica também que todos se graduaram durante a década de 2000 e que o curso de Especialização em Educação, Pobreza e Desigualdade social tem sido, para a grande maioria, a primeira oportunidade de pós-graduação. As razões para cursar a referida Especialização, conforme explicitadas nas "cartas de intenções", documento requerido no momento da inscrição no curso, estão ligadas diretamente à atuação profissional e podem ser agrupadas em duas categorias básicas: 1) Melhorar a atuação, seja na docência, seja na implementação de políticas e programas de assistência social; 2) Contribuir para a melhoria das condições de vida dos beneficiários dos programas e das políticas de educação e assistência social. Deve-se destacar, ao tomar as cartas como uma fonte de dados visando caracterizar a população, que essas são um documento escrito com a finalidade de convencer os avaliadores das "intenções" do candidato, portanto, com forte teor retórico. A análise do seu conteúdo, por isso exige um rigor epistemológico mais acurado, quando, por exemplo, são essas confrontadas com outras fontes de dados. Além dessas justificativas, alegou-se o interesse em "aprimorar-se intelectualmente", "dar continuidade aos estudos", especialmente no aprofundamento de conhecimentos sobre educação, pobreza, desigualdades e políticas públicas (exatamente o que oferta a proposta do curso - ver ressalva anterior).

Em termos de distribuição dos cursistas por gênero, o grupo pesquisado é formado majoritariamente por mulheres (83\%); apenas 17\% são homens. Quanto à idade, $49,5 \%$ concentram-se nas faixas de $25-30(25,6 \%)$ e $31-35(23,9 \%)$, indicando a predominância de jovens profissionais em início de carreira. As demais faixas se distribuem em percentuais bem menores. Quanto ao estado 
civil, dentre os que responderam à questão, 52,6\% declararam-se casados e $37,5 \%$ solteiros. No tocante à raça/etnia, $45,8 \%$ declararam-se brancos, $8,6 \%$ negros e $41,5 \%$ pardos, e os demais não responderam.

\section{A estrutura dos conteúdos representacionais sobre o objeto simbólico "pobreza"}

Apresentamos, a seguir, o resultado das análises dos dados, feitas a partir da utilização da TALP. Os dados relativos às evocações e coletados por meio do questionário de associação livre foram inicialmente organizados em um arquivo criado no Excel, depois submetidos ao processamento do EVOC (VERGÈS, 2005). Em outro arquivo, desta vez no Microsoft Word, foram organizados apenas os textos das justificativas dadas às palavras consideradas mais importantes, visando submetê-las à análise categorial de conteúdo, conforme orientam, dentre outros, autores como Bauer e Gaskell (2002) e Franco (2005).

O questionário, como já dito, foi entregue aos 377 cursistas, dos 400 matriculados, presentes na aula inaugural, mas apenas 301 foram devolvidos. Desses, 25 não preencheram as condições para o tratamento e análise pelo EVOC, o que resultou no total de 276 questionários válidos. Os cursistas que responderam ao questionário foram distribuídos pelos polos e respectivos municípios aos quais estavam vinculados até aquele momento (Tabela 1). Os polos são estruturas de apoio para o desenvolvimento do curso, localizados em municípios de diferentes regiões do estado, e possuem laboratórios de informática, bibliotecas e secretarias acadêmicas. Neles se realizam os encontros entre os "tutores presenciais" e os alunos.

No cômputo geral, foram evocadas 1032 palavras, sendo 324 diferentes, correspondendo a $31,4 \%$ do total. Observamos, ainda, que 217 palavras foram evocadas uma única vez, o equivalente a $21 \%$ do total; ou seja, quase um quarto das evocações foi de palavras evocadas uma única vez, indicando a diversidade de formas de referir-se ao objeto simbólico "pobreza". O que está, por sua vez, relacionado à heterogeneidade da composição da população: origem social, formação profissional, distribuição geográfica e inserção em diferentes sistemas culturais representados pelos municípios e regiões do estado e visões ideológicas em relação ao fenômeno da pobreza, como se verá na análise das justificativas dadas às evocações consideradas as mais importantes. 
TABELA 1 - DISTRIBUIÇÃO DOS QUESTIONÁRIOS RESPONDIDOS POR POLO/TURMA

\begin{tabular}{l|c|c}
\hline \multicolumn{1}{c|}{ POLO / TURMA } & N & $\mathbf{\%}$ \\
\hline CAICÓ & 37 & $12 \%$ \\
\hline CARAÚBAS & 26 & $9 \%$ \\
\hline CURRAIS NOVOS & 25 & $8 \%$ \\
\hline GROSSOS & 13 & $4 \%$ \\
\hline MACAU & 15 & $5 \%$ \\
\hline MARTINS & 24 & $8 \%$ \\
\hline NATAL 1 & 33 & $11 \%$ \\
\hline NATAL 2 & 38 & $13 \%$ \\
\hline NATAL 3 & 35 & $12 \%$ \\
\hline NOVA CRUZ & 33 & $11 \%$ \\
\hline PARNAMIRIM & 22 & $\mathbf{7 \%}$ \\
\hline TOTAL & $\mathbf{3 0 1}$ & $\mathbf{1 0 0 \%}$ \\
\hline
\end{tabular}

FONTE: crédito das autoras. Dados obtidos por meio do questionário da TALP e das fichas de identificação dos cursistas.

O software EVOC (VERGÈS, 2005) gerou ao final o quadro de quatro casas apresentado a seguir, no qual se distribuem os elementos representacionais referentes ao objeto em estudo.

QUADRO 1 - CONFIGURAÇÃO ESTRUTURAL DOS CONTEÚDOS REPRESENTACIONAIS SOBRE O OBJETO POBREZA

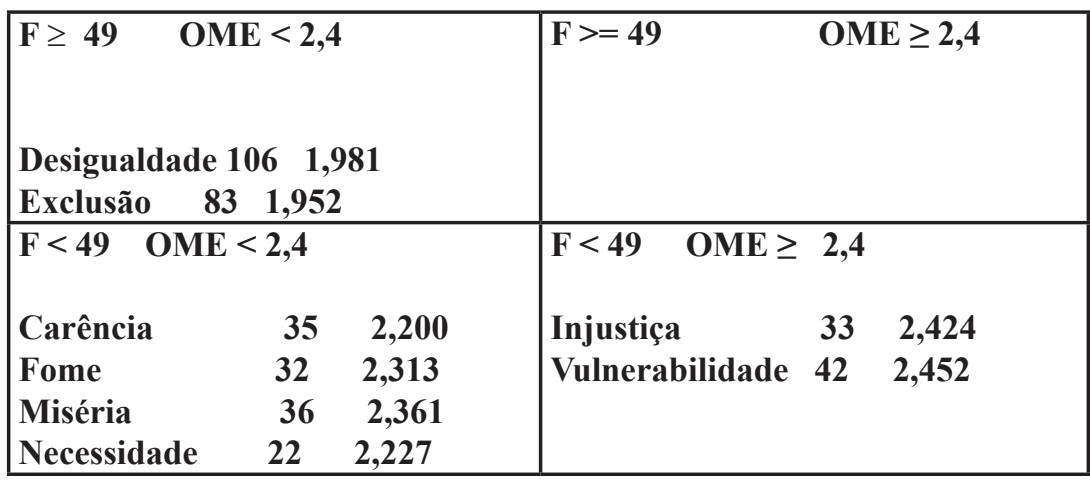

FONTE: crédito das autoras. Processamento e análise feita pelo software EVOC (VERGÈS, 2005).

No quadrante superior esquerdo, situam-se os elementos com frequência maior ou igual a 49 e ordem média de evocação (OME) menor que 2,4; são 
eles: desigualdade e exclusão. Constatamos que o termo "desigualdade" foi evocado 106 vezes e "exclusão" evocado 83 vezes, e obtiveram ordem média de evocação igual a 1,981 e 1,952 respectivamente. De acordo com Abric (2000), o quadrante superior à esquerda não é necessariamente o núcleo central, mas o núcleo central de uma representação poderá ser encontrado nele, pois aí estão as palavras de maior frequência e prontamente evocadas. Portanto, essas são mais consensuais e fundantes de uma representação social. As palavras que se encontram em tais circunstâncias estão em consonância com critérios estatísticos (maior a frequência e menor ordem média de evocação) e são indicadores de pertença do núcleo central.

No quadrante superior direito, localizam-se os elementos com frequência elevada, porém evocadas tardiamente. Em geral, os elementos constantes nesse quadrante mantêm uma aproximação de sentido com as palavras que compõem o núcleo central. No entanto, na presente pesquisa, nenhuma palavra evocada atendeu a esses requisitos do EVOC e o quadrante ficou vazio. Tal fato pode ser um indicativo de dispersão ou falta de consenso do grupo investigado, segundo a teoria. Por essa razão, destacamos anteriormente que 217 palavras foram evocadas uma única vez, o equivalente a $21 \%$ do total, ou seja, quase um quarto das evocações. Supomos que isso possa ser atribuído à dispersão e à falta de consenso sobre a percepção de certos aspectos do objeto representado. O que não ocorre quanto aos aspectos mais compartilhados presentes no quadrante superior esquerdo.

No quadrante inferior esquerdo, aparecem os elementos com frequência menor que 49 e ordem média de evocação inferior a 2,4. Essas palavras foram prontamente citadas, mas com baixa frequência e, por isso, consideradas elementos periféricos em relação ao provável núcleo central. Nessas condições estão os termos: carência (F35, OME 2,200), fome (F32, OME 2,313), miséria (F36, OME 2,361) e necessidade (F22, OME 2,227).

O quadrante inferior direito apresenta elementos com frequência inferior a 49, indicando que foram lembrados por último, pois estão com a média acima ou igual à ordem média das evocações: 2,4 . As palavras com tais características (menor frequência e lembradas tardiamente) situam-se, igualmente, em uma zona periférica em relação ao núcleo central. Com esta configuração, encontramos: injustiça (F 33, OME 2,424) e vulnerabilidade (F42, OME 2,452).

O levantamento do núcleo central é relevante, pois oferece ao pesquisador a possibilidade de conhecer qual de fato é o objeto da representação. Abric (1994, p. 24, tradução livre) afirma: “[...] qualquer objeto não é necessariamente objeto de representação. Para que um objeto seja objeto de representação, é necessário que os elementos organizadores de sua representação façam parte ou sejam diretamente associados ao próprio objeto.” Isso porque há representações cujos 
elementos organizadores, isto é, os quais lhe dão coerência, estão interligados há outros objetos (seriam representações sociais não autônomas, o que foge da nossa discussão aqui). No caso em tela, pode-se perceber que todos os elementos que dão coerência ao conteúdo identificado referem-se ao objeto "pobreza".

Essa organização estrutural do conteúdo representacional é também importante para se compreender que, não obstante as variações semânticas e as aparentes contradições discursivas, subsiste uma coerência na totalidade dos elementos, responsável, dentre outras funções, pela existência de uma função: a) geradora - os elementos do núcleo central são a base a partir da qual se cria ou se transforma a significação dos demais elementos da representação; b) organizadora - é o núcleo central que determina a natureza dos laços que unem todos os demais elementos. Acrescenta Abric (1994, p. 22): "Ele [o núcleo central] constitui o elemento mais estável da representação, aquele que lhe assegura a perenidade em contextos móveis e evolutivos".

\section{Análise das justificativas dadas à palavra considerada a mais importante}

$\mathrm{Na}$ terceira fase do questionário, solicita-se que o sujeito escreva uma justificativa para a palavra considerada a mais importante. Trata-se, portanto, de uma etapa na qual se pede a produção de um discurso de caráter mais racionalizado sobre o objeto. Os discursos assim produzidos foram analisados com base no método de análise de conteúdo, conforme Bauer e Gaskell (2002) e Franco (2005). A unidade de análise foi a categoria, o que nos permitiu sistematizar, identificar as relações semânticas e buscar a coerência, explícita ou subjacente, entre os diversos enunciados relativos aos dois elementos do núcleo central das evocações produzidas: "desigualdade" e "exclusão". A partir dessa análise, pôde-se inferir, com base no modelo moscoviciano, que a estruturação das evocações aponta para os seguintes resultados: a) a existência de discursos sobre o objeto que indicam uma leitura de caráter científico, portanto, não fazendo parte do que Serge Moscovici denomina de representações sociais; b) a existência de produções discursivas que indicam a presença de representações de caráter ideológico, ideologia aqui entendida como visão de mundo compartilhada por determinado conjunto de indivíduos; c) uma representação social tal como conceitua a teoria. Antes, porém, de explicitarmos esses resultados, algumas considerações de caráter epistemológico precisam ser feitas. 
Na opinião de Abric (2000), a centralidade de um elemento, embora deva ser atribuída a critérios quantitativos e qualitativos, define-se mais pela dimensão qualitativa que o elemento oferece à representação do que pela sua presença expressiva do ponto de vista quantitativo. Nessa direção, Sá (1996) apresenta as quatro propriedades relativas às cognições centrais: valor simbólico, poder associativo, saliência e forte conexidade na estrutura. As duas primeiras são qualitativas, ditadas pela teoria das representações sociais; as duas últimas são quantitativas e decorrem das anteriores.

O valor simbólico reside no fato de o elemento central manter com o objeto da representação uma estreita relação, não podendo ser dissociado deste. Do contrário, o objeto representado perderia de todo a sua significação. O poder associativo refere-se à sua forte relação com os demais elementos da representação. Já a saliência e a forte conexidade na estrutura, resultante das duas características anteriores, são mais facilmente identificadas por meios quantitativos, como ilustrado no quadro de quatro casas do EVOC. Assim, "desigualdade" e "exclusão" são sentidos estreitamente vinculados ao objeto "pobreza", daí destacar-se o seu valor simbólico e poder associativo em relação aos demais elementos que emergem do processo de associação de palavras e figuram nos quadrantes onde se encontram os elementos periféricos.

Outro princípio a considerar: o núcleo central é sempre composto por um ou alguns elementos que dão visibilidade ao resultado do trabalho coletivo para objetivar o objeto representado, isto é, dar-lhe uma existência concreta para o grupo, e ancorá-lo, isto é, atribuir-lhe um sentido que o torne familiar - dois processos fundamentais na construção de uma representação social. Esclarecendo: o processo de objetivação, para Moscovici (1978), está relacionado à construção da face imagética da representação, ou seja, ao processo pelo qual o que é abstrato passa a assumir uma presença quase tangível para os sujeitos. O conceito abstrato de "pobreza", neste caso, é objetivado como desigualdade, exclusão, fome, miséria, necessidade, por exemplo.

O mesmo acontece com a ancoragem, processo através do qual o desconhecido torna-se familiar porque passa a ser significado com base nos referentes culturais, históricos e identitários do grupo. Nesta pesquisa, a ancoragem do objeto representacional "pobreza", efetiva-se em injustiça, vulnerabilidade, má distribuição de renda, falta de educação. Necessário enfatizar que Moscovici sempre alertou para não se separar esses dois processos, principais responsáveis pela estruturação da representação social dada pelos componentes figura/ significado, tão interligados como as duas faces de uma moeda. Inútil perguntar quem vem antes ou depois.

Com base no que dissemos acima sobre os resultados das análises das justificativas, no primeiro caso, encontramos discursos sobre o objeto que fazem 
referência a uma explicação de caráter científico, portanto, não se confundindo com as representações do objeto que expressam um conhecimento "ingênuo" sobre ele ou que o reduzem ao seu aspecto econômico, ao papel das políticas públicas ou ainda à educação como saída redentora, conforme se apresenta a seguir:

Vivemos em uma sociedade capitalista, neste tipo de modo de produção a renda que é socialmente produzida não é distribuída coletivamente, ou seja, é privada, causando cada vez mais as desigualdades sociais. A pobreza, portanto, é produzida e reproduzida socialmente, causando nesta população cada vez mais vulnerabilidade e risco social. Mas a pobreza não é apenas ausência ou dificuldade de acesso aos direitos; é também e, principalmente, ausência de possibilidades de enfrentamento às questões sociais que são reflexos desse modo de produção. (Natal III).

A desigualdade gerada pelo modo de produção capitalista se agrava mais com o estado mínimo, caracterizado pela ausência de políticas públicas que atendam aos direitos básicos do cidadão, gerando a falta de acesso destes aos direitos sociais legalmente instituídos, porém não efetivados, agravando a pobreza e a extrema pobreza em nossa sociedade. (Parnamirim).

No segundo caso, o das representações ideológicas, a face icônica do objeto "materializa-se" na forma pela qual é percebido, e a ancoragem se dá com base em conhecimentos de cunho econômico, político e educacional e assume uma conotação crítico-ideológica. A estrutura dessa representação pode ser ilustrada como se segue:

\section{Desigualdades/Desigualdades sociais (econômica e educacional) Má distribuição de renda/Falta de educação}

A desigualdade está ligada diretamente à pobreza, uma vez que o acúmulo e a má distribuição de renda fomentam o processo de exclusão social (Natal I).

A desigualdade social é produto da inexistência de políticas públicas voltadas à educação com ênfase no desenvolvimento social que tem 
também como fonte social a estabilidade no contexto em tela. O emprego e renda são consequências desse recorte. Por isso, a educação ainda é a ferramenta disponível para combater essa desigualdade social que assola a nossa sociedade. (Natal II).

A escolha dessa palavra "desigualdade" se dá através da atual falta de oportunidade e acesso à educação pois é claramente visualizado em nosso país, que as maiores oportunidades são ofertadas a classe "A" (elite). (Parnamirim).

Diferentemente das justificativas do primeiro caso, quando se faz apelo às teorias econômicas e políticas para explicar o porquê de se ter considerado "desigualdade" como a palavra considerada a mais importante, no segundo caso, mesmo se fazendo apelo aos elementos de ordem econômica e política, o central é a explicitação de opiniões vinculadas a uma visão crítica do mundo, mas sem a clareza e consistência teórica das primeiras. Esses discursos podem ser classificados como pertencentes a uma representação social de caráter ideológico, como enfatiza Jodelet (2001, p. 32): "Certamente, há representações que cabem em nós como uma luva ou que atravessam os indivíduos: as impostas pela ideologia dominante ou as que estão ligadas a uma condição definida no seio da estrutura social", ou seja, fruto da relação ideológica que se mantém com o mundo social.

O terceiro caso refere-se à estruturação de uma representação social no sentido clássico defendido por Moscovici, posto que os elementos centrais "desigualdade" e "exclusão" são interpretados segundo uma leitura sem enfoque crítico no econômico, nas políticas públicas ou na educação. A face icônica é preservada, mudando, no entanto, a ancoragem, isto é, o significado atribuído ao objeto. Destaca-se a visão do fenômeno como intrínseco à sociedade brasileira (ou às sociedades humanas) sem nenhuma acentuação crítica, como no caso anterior: Desigualdade $=$ Face icônica $/$ Realidade social $=$ Significado .

A pobreza está relacionada com as desigualdades sociais, pois vivemos em um mundo onde existem pessoas que vivem em extrema pobreza e outros que têm todos os recursos necessários para sua sobrevivência. (Itaú).

A desigualdade e a pobreza são problemas que afetam a maioria dos países na atualidade. A pobreza está em todos os países ricos ou pobres, mas a 
desigualdade social é um fenômeno que ocorre principalmente em países não desenvolvidos. (Paraú).

Desigualdade, há uma desigualdade social em nossa sociedade, com isso causando uma indiferença entre os mesmos. (Caicó).

Esses resultados permitem-nos constatar o que diz a teoria, por exemplo, quanto ao estatuto epistemológico de uma representação social, isto é, que se trata de um conhecimento sociocêntrico, a serviço das necessidades, dos desejos e dos interesses do grupo, por isso uma reconstrução do objeto em que ocorrem operações de ordem cognitiva, que levam a distorcer ou a suprimir características inerentes ao objeto ou a acrescentar outras. Por exemplo, os discursos da representação ideológica podem ser interpretados como reduzindo o fenômeno da pobreza às dimensões econômica e política, portanto, sem fazer menção a outras dimensões de sua produção - operação mental de subtração, por um lado, e, por outro, de distorção do peso das dimensões citadas; ou dando-se exclusividade ao papel da educação na sua superação, por conseguinte, "adicionando-se" outro elemento explicativo.

Outra observação teórica é ainda oportuna ser feita. É possível perceber como os discursos das justificativas são influenciados por teorias educacionais ou do serviço social, embora não se confundam, como já afirmado, com explicações de caráter científico; assim como influenciados por opiniões diversas, oriundas do senso comum, como crenças variadas que circulam na cultura regional, além de expressarem aspectos afetivos dos sujeitos na sua relação com o objeto, dentre outros. A esse fenômeno, intrínseco às representações sociais, Moscovici chamou de polifasia cognitiva. Isso ocorre porque essas são diferentes das representações profissionais ou científicas; contudo, não em razão de um defeito de estrutura, de uma insuficiência lógica ou de um desconhecimento entre as noções assim combinadas, mas porque é de sua natureza combinar vários domínios do conhecimento e da prática, ao mesmo tempo que vários modos de pensar (MOSCOVICI, 1989). Por essa razão, o discurso representacional está sempre expressando tensões, ambiguidades e contradições, ao contrário das produções discursivas conduzidas essencialmente pela razão, lógica e coerência, como o discurso científico.

Não obstante essas características, as representações sociais traduzem um consenso, por isso o adjetivo "social". E isso não tem a ver com o número de sujeitos que a compartilham, pois o que confere especificidade a uma representação não é tanto o maior ou menor número de sujeitos, mas a sua função 
de "guia para a ação", ou seja, como sublinhou Moscovici (1978), o seu papel na formação de condutas e orientação das comunicações. Para evidenciar isso, preferimos, na indicação dos trechos dos discursos citados, destacar o nome do município de onde provém a fala, a fim de ilustrar a força simbólica dos elementos centrais e o seu forte poder associativo com todos os demais elementos da estrutura. Por essa razão, também decidimos apresentar na Tabela 1 a lista dos municípios onde se situa a população investigada - mesmo que não tivéssemos espaço aqui para demonstrá-lo - a fim de reforçar com isso que, não é fundamental a distância ou proximidade física ou geográfica entre os sujeitos, o que importa é a adesão a uma forma de pensamento sobre a realidade, pois, como diz Jodelet (2001, p. 34): "Partilhar uma ideia ou uma linguagem é também afirmar um vínculo social e uma identidade [...]. A partilha serve à afirmação simbólica de uma unidade e de uma pertença. A adesão coletiva contribui para o estabelecimento e o reforço do vínculo social".

\section{Considerações finais}

Os resultados da pesquisa realizada no âmbito da Iniciativa Educação, Pobreza e Desigualdade Social, aqui brevemente apresentados, permitem-nos refletir principalmente sobre dois achados considerados por nós os mais importantes do ponto prático: a existência de uma representação social de caráter ideológico sobre o objeto pesquisado e, de outra, que naturaliza o fenômeno da pobreza e das desigualdades. A importância dessa reflexão ampara-se no estatuto epistemológico das representações sociais (é fundamental insistir no adjetivo "social") e na sua função social o que as distingue de todas as demais produções mentais pesquisadas pela Psicologia Cognitiva e pela Psicologia Social, como sempre defenderam Serge Moscovici e Denise Jodelet (criador e divulgadora da teoria) e seus seguidores mais conceituados no mundo, cuja lista é bastante longa. Este campo de pesquisa já possui mais de cinquenta anos de atividades.

Do ponto de vista de seu estatuto epistemológico e sua função social, como já ressaltado, as representações sociais são um conhecimento sociocêntrico com um caráter prático, portanto, voltado para a ação e a gestão das relações com o mundo. Os sujeitos que compartilham uma representação ideológica sobre o objeto, na sua maioria assistentes sociais e educadores situados na região da Grande Natal, formados na UFRN ou em faculdades da capital, fazem uma transposição das teorias estudadas e informações sobre o objeto, durante os processos de objetivação e ancoragem, que podem ter implicações práticas rele- 
vantes, posto que reduzem a complexidade e multidimensionalidade da produção e reprodução do fenômeno ao qual se refere o objeto simbolizado "pobreza".

No caso da representação que naturaliza a existência da pobreza como fenômeno inerente à sociedade brasileira ou às sociedades humanas em geral, os processos de objetivação e ancoragem se efetivam a partir de outros referentes culturais e informações que precisam ser melhor conhecidos. É importante destacar que nessa população encontram-se assistentes sociais e educadores, sempre em maior número, residindo em municípios mais afastados da região metropolitana, por conseguinte sem maiores contatos com universidades, faculdades e um ambiente de maior circulação de informações e debates acadêmicos sobre a temática.

Os resultados indicam, pois, a necessidade de uma melhor e mais ampla utilização dos achados, tendo em vista servirem como suportes à elaboração de estratégias que visem promover a ressignificação dos elementos centrais e de outros elementos periféricos de maior saliência e conexidade na estruturação dos conteúdos representacionais, levando-se em conta as particularidades de cada realidade onde atuam as políticas voltadas ao enfrentamento da pobreza e desigualdades sociais. Como dizem Abric e todos os teóricos do Núcleo Central, para que uma representação social mude é necessário promover a mudança dos elementos que a estruturam, pois são esses que lhe asseguram a estabilidade e a continuidade no tempo.

\section{REFERÊNCIAS}

ABRIC, J. C. A abordagem estrutural das representações sociais. In: MOREIRA, A. S. P.; OLIVEIRA, D. C. (Orgs.). Estudos interdisciplinares de Representações Sociais. 2. ed. Goiânia: AB, 2000. p. 27-38.

ABRIC, J. C. Méthodologie de recueil des représentations sociales. In: ABRIC, J.-C. (Org.). Pratiques e representations sociales. Paris: Presse Universitaires de France, 1994. p. 59-82.

BAUER, M. W.; GASKELL, G. Pesquisa qualitativa com texto, som e imagem: um manual prático. Petrópolis: Vozes, 2002.

DOMINGOS SOBRINHO, M. Habitus e representações sociais: questões para o estudo de identidades coletivas. In: MOREIRA, A. S. P.; OLIVEIRA, D. C. de (Orgs.). Estudos interdisciplinares de representação social. 2 ed. Goiânia: AB, 2000. p. 117-159.

FRANCO, M. L. P. B. Análise de conteúdo. 2 ed. Brasília: Líber Livro Editora, 2005. 
JODELET, D. Representações sociais: um domínio em expansão. In: JODELET, D. (Org.). As Representações Sociais. Rio de Janeiro: EdUERJ, 2001, p. 17-44.

MOSCOVICI, S. Prefácio. In: JODELET, D. Folies et Représentations Sociales. Paris: PUF, 1989. p. 09-30.

MOSCOVICI, S. La psychanalyse, son image, son public. Paris: PUF, 1978.

OLIVEIRA, D. C. de et al. Análise das evocações livres: uma técnica de análise estrutural das representações sociais. In: MOREIRA, A. S. P. (Org.). Perspectivas teórico-metodológicas em representações sociais. João Pessoa: UFPB/Ed. Universitária, 2005. p. 573-603.

SÁ, C. P. Núcleo central das representações sociais. Petrópolis: Vozes, 1996.

VERGÈS, P. Ensemble de Programmes permettant l'analyse des evocations. Aix en Provence, Version 2, abril, 2005.

Texto recebido em 24 de março de 2017.

Texto aprovado em 12 de abril 2017. 